\title{
Aluminium Substituted Magnetite by Wet Method
}

\author{
Y. Okano, N. Uchida and T. Nakamura \\ R\&D division, Toda Kogyo Corporation, 4-1-2, Funairi-minami, Naka-ku, Hiroshima 730, Japan
}

\begin{abstract}
Aluminium substituted magnetite particles with $\mathrm{Al}^{3+}$ content in the range from 0.7 to $4.0 \mathrm{wt} \%$ were synthesized by the hydrothermal oxidation reaction. It was found that the mixing procedure was critical to prepare single-phase ferrite particles : it was required that $\mathrm{Al}$ ions were neutralized before the precipitation of $\mathrm{Fe}$ ions. As the aluminium content increases, the magnetization of the obtained particles decreased in the range from 86 to $60 \mathrm{emu} / \mathrm{g}$. The lattice constant also decreased from 0.840 to $0.836 \mathrm{~nm}$. XPS analysis indicated that aluminium in the obtained particles was both in hydroxide and oxide states, and that the molar fraction of them was approximately $20 \%$ and $80 \%$, respectively. The lattice constant was in good agreement with the calculated value using the Vegard's law in $\mathrm{Fe}_{3} \mathrm{O}_{4}-\gamma-\mathrm{Fe}_{2} \mathrm{O}_{3}-\mathrm{FeAl}_{2} \mathrm{O}_{4}$ solid solution and taking into account of the existence of aluminium hydroxide.
\end{abstract}

\section{INTRODUCTION}

Ferrite has been widely used in many application such as electromagnetic devices and magnetic inks. The electric and magnetic properties of ferrite depend on the cation configuration in the spinel lattice, which consists of tetrahedral and octahedral interstitial sites. The cation distribution in the spinel lattice is controlled by many factors such as the kind of the cation, the ionic radius and the valence state. In addition, the cation distribution is not always in thermal equilibrium state. therefore, it depends on the sample preparation route. From this point of view, it is expected that hydrothermal-synthesized ferrite possesses unique property in comparison with ferrite prepared by ceramic method[1,2.3]. In this paper, we ve investigated the method for synthesis of the aluminium substituted magnetite particles by the aerial oxidation. and then briefly discussed the stoichiometry and the aluminium distribution in the obtained particles.

\section{EXPERIMENTAL PROCEDURE}

The following three mixing methods of aluminium sulfate, ferrous sulfate and sodium hydroxide solutions were employed. In the first case, after ferrous sulfate solution was mixed with sodium hydroxide solution. aluminium sulfate solution was added in the suspension of ferrous hydroxide (this denotes method A). In the second case, aluminium sulfate solution was mixed with sodium hydroxide solution, and then ferrous sulfate solution was added in the mixed solution (method B). In the last case, the mixed solution of aluminium sulfate and ferrous sulfate was added in a sodium hydroxide solution (method $\mathrm{C}$ ). These mixing procedure were carried out at $90^{\circ} \mathrm{C}$ under $\mathrm{N}_{2}$-bubbling to avoid the oxidation of ferrous ion during the mixing. The $\mathrm{Al}^{3+} / \mathrm{Fe}^{2+}$ ratio in the initial hydroxide suspensions was adjusted from 0.05 to 0.33 . and the total amount of $\mathrm{Al}^{3+}$ and $\mathrm{Fe}^{2+}$ was kept constant at $0.8 \mathrm{~mol} / \mathrm{dm}^{3}$.

The air-flow was put through the above hydroxide suspensions under mechanical stirring, where the temperature of the suspensions were kept at approximately $90^{\circ} \mathrm{C}$. The $\mathrm{pH}$ value during the oxidation reaction was kept at approximately 10.5 with the titration of diluted sodium hydroxide solution. After the completion of the oxidation, the pH value of the obtained suspension was adjusted to approximately 11.5 with diluted sodium hydroxide solution in order to remove unreacted aluminium ions. Then the precipitates were filtrated, washed with distilled water and dried in air at $60^{\circ} \mathrm{C}$.

\section{RESULTS AND DISCUSSION}

The method B provided only granular particles, the X-ray diffraction pattern of which showed only spinel structure. In the cases of the method $\mathrm{A}$ and $\mathrm{C}$, granular particles were formed with irregular-shaped particles. X-ray diffraction patterns for these products indicated the mixture of the spinel phase and a small amount of $\alpha$-ferric oxyliydroxide, and that the fraction of $\alpha$-ferric oxyhydroxide prepared by the method $C$ was less than that by the method $A$. Therefore, it is found that the method $B$ is the most suitable mixing procedure for synthesis of aluminium substituted magnetite particles. 
Next, we discuss the properties of the aluminium substituted magnetite particles synthesized by the method B. The magnetization decreased in the range from 86 to $60 \mathrm{emu} / \mathrm{g}$ with an increase in $\mathrm{Al}^{3+}$ content from 0.70 to $4.0 \mathrm{wt} \%$. The decrease of the magnetization can be explained by the substitution of diamagnetic $\mathrm{Al}^{3+}$ for $\mathrm{Fe}^{3+}$ in octahedral site. The lattice constant of the obtained spinel phase decreased from 0.840 to $0.836 \mathrm{~nm}$ with an increase of the $\mathrm{Al}^{3+}$ content with the above range, as expected from the ionic radius difference between $\mathrm{Fe}^{3+}(0.79 \AA)$ and $\mathrm{Al}^{3+}(0.68 \AA)$. But the lattice constant variation deviated from the simple Vegard's law, in which the obtained particles were assumed to be $\mathrm{Fe}_{3-\mathrm{x}} \mathrm{Al}_{\mathrm{x}} \mathrm{O}_{4}$.

In order to clarify the reason for the deviation from the simple Vegard's law, we performed X-ray photoelectron spectroscopic measurement of $\mathrm{Al}(2 \mathrm{p})$. First, we measured the $\mathrm{Al}(2 \mathrm{p})$ spectra of aluminium hydroxide and aluminium substituted magnetite prepared by conventional ceramic technique. The spectra was numerically fitted to Lorentzian functions : center at $76.2 \mathrm{eV}$ and a width of $2.1 \mathrm{eV}$ for aluminium hydroxide. center at $75.0 \mathrm{eV}$ and a width of $2.0 \mathrm{eV}$ for aluminium substituted magnetite. Then, the XPS spectra for the obtained particles with $\mathrm{Al}^{3+}$ content of $3.5 \mathrm{wt} \%$ were measured. Figure 1 indicates that the XPS spectnum of $\mathrm{Al}(2 \mathrm{p})$ consisted of a broad signal. It was reproduced by the superposition of the above two Lorentzian functions, and the chemical states of Al were determined by their percentages in the various states. The Al percentage in oxide state was approximately $80 \%$ and that in hydroxide state was approximately $20 \%$. It implies that a part of aluminium are not incorporated into the spinel lattice but precipitated out of the ferrite particles. probably at grain boundary and particle surface. It may be attributed to the difference of hydrolytic precipitation rate between $\mathrm{Fe}$ and $\mathrm{Al}$ ions.

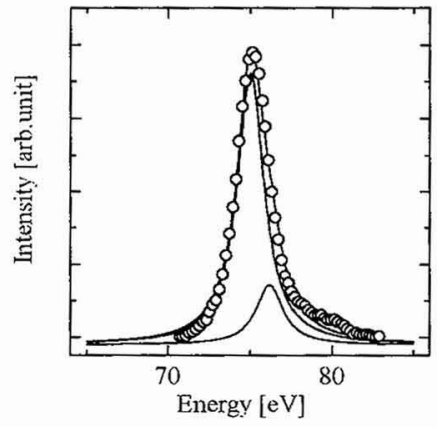

Fig.1 XPS spectrum of $\mathrm{Al}(2 \mathrm{p})$ in the obtained particles.

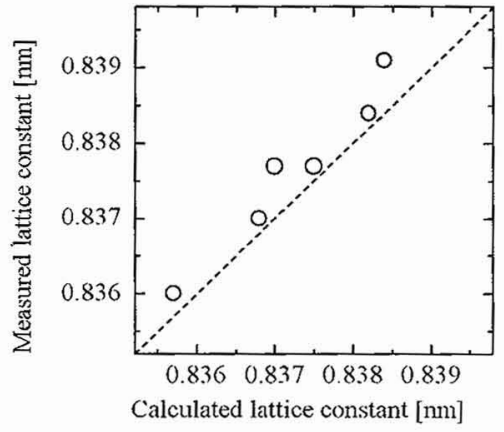

Fig.2 The measured lattice constant versus the lattice constant calculated from the Vegard's law

Detail discussion on the lattice constant variation of the obtained spinel phase needs the corrected Al content which is estimated by subtraction of $\mathrm{Al}$ content in hydroxide state from the total Al content. Furthermore, the ferrous content deviated from the stoichiometric value because of some oxidation degree during drying process. Therefore, it is considered that the spinel phase is $\mathrm{Fe}_{3} \mathrm{O}_{4}-\gamma-\mathrm{Fe}_{2} \mathrm{O}_{3}-\mathrm{FeAl}_{2} \mathrm{O}_{4}$ solid solution. Figure 2 shows the measured lattice constant versus the lattice constant calculated from the Vegard's law, in which the obtained particles assumed to be composed of aluminium hydroxide and the above mentioned solid solution. The values of $0.8397,0.8350$ and $0.8146 \mathrm{~nm}$ were used as the lattice constant of $\mathrm{Fe}_{3} \mathrm{O}_{4}$, $\gamma-\mathrm{Fe}_{2} \mathrm{O}_{3}$ and $\mathrm{FeAl}_{2} \mathrm{O}_{4}$, respectively. A dashed line represents the values calculated using the Vegard's law. From this figure. it is seen that the lattice constant is in good agreement with those calculated using the Vegard's law. Accordingly. the deviation from the simple Vegard's law is attributed to the existence of aluminium hydroxide and $\gamma-\mathrm{Fe}_{2} \mathrm{O}_{3}$ which is formed during drying process.

\section{CONCLUSION}

The aluminium substituted magnetite particles with $\mathrm{Al}^{3+}$ content up to $4.0 \mathrm{wt} \%$ were synthesized by the hydrothermal oxidation reaction of aqueous suspensions. It was found that the mixing procedure was critical to prepare single-phase ferrite particles: it was required that $\mathrm{Al}$ ions were neutralized betore the precipitation of $\mathrm{Fe}$ ions. It is clarified that the obtained particles have nonuniform aluminium distribution : a part of aluminium are precipitated as hydroxide state at grain boundary and particle surface. Consequently, the measured lattice constant is in good agreement with the lattice constant calculated from the Vegard' law, considering that the obtained particles consists of aluminium hydroxide and $\mathrm{Fe}_{3} \mathrm{O}_{4}-\gamma-\mathrm{Fe}_{2} \mathrm{O}_{3}-\mathrm{FeAl}_{2} \mathrm{O}_{4}$ solid solution.

\section{References}

[1] M. Kiyama and T. Takada, Proceedings of the 3rd International Conference on Ferrites., (1980) 11-14

[2] M. Kiyama, Bull. Chem. Soc. Jpn., 51 (1978) 134

[3] T. Sato, K. Haneda, M. Seki and T. Iijima, Proc. Intern. Sympo. Physics of Magnetic Materials (World Scientific. Singapore) (1987) 210 